\title{
RANCANG BANGUN PURWARUPA KLASIFIKASI WARNA OBJEK MENGGUNAKAN ROBOT LENGAN 4-DOF
}

\author{
Prima Asmara Sejati ${ }^{1}$, Adhi Susanto ${ }^{2}$ \\ ${ }^{1}$ Departemen Teknik Elektro dan Informatika, Sekolah Vokasi, Universitas Gadjah Mada \\ Yogyakarta, Indonesia \\ ${ }^{2}$ Departemen Teknik Elektro dan Teknologi Informasi, Fakultas Teknik, Universitas Gadjah \\ Mada \\ Yogyakarta, Indonesia
}

e-mail: prima.asmara.s@ugm.ac.id,susanto@te.ugm.ac.id

\begin{abstract}
Abstrak
Robot lengan merupakan salah satu aplikasi robotika yang telah banyak diterapkan di dunia industri. Penelitian ini menerapkan salah satu aplikasi dari robot lengan 4-DOF dengan gripper end effectornya. Robot ini berfungsi sebagai pengklasifikasi objek berdasarkan warna objek secara otomatis. Secara keseluruhan, sistem otomasi ini terdiri dari robot lengan, konveyor statis, dan wadah sesuai warna (merah, biru, hijau, dan hitam). Sistem ini terdiri dari sensor warna RGB satu pixel, mikrokontroller sebagai prosessor, dan 6 buah servo sebagai aktuator. Sensor RGB berfungsi sebagai masukan yang diproses melalui mikrokontroler dan dilakukan perhitungan jumlah objek berdasarkan warna. Untuk penentuan posisi target peletakan objek digunakan metode pemetaan arena. Posisi ini dapat diatur secara manual dan kemudian disimpan di memori mikrokontroler sebagai acuan aksi robot lengan. Hasil penelitian ini menunjukkan bahwa robot lengan dapat mendeteksi dan mengklasifikasi objek berwarna merah dengan waktu 10 detik, hijau 8,9 detik, biru 8 detik, dan hitam 9,9 detik.
\end{abstract}

Kata kunci: robot lengan, sensor warna, klasifikasi objek,

\begin{abstract}
Arm robot is one of the robotics applications that have been widely applied in the industrial process. This research represent one of the application of 4-DOF arm robot with gripper as end effector. This robot serves as the object classifier based on the color of the object. This automation system consists of arm robots, static conveyors, and colored containers (red, blue, green, and black). This system consists of a single pixel RGB color sensor, microcontroller as a processor, and 6 servo as actuator. The function of RGB sensor is as an input that is processed through a microcontroller and calculates the number of objects by color. Arena mapping method is used for object positioning target. This position can be set manually and then stored in the microcontroller memory as a reference for the arm robot action. The results of this study shows that arm robots can detect and classify red objects with time of 10 seconds, green 8.9 seconds, blue 8 seconds, and black 9.9 seconds.
\end{abstract}

Keywords : arm robot, color sensor, object classification

\section{PENDAHULUAN}

Dengan semakin berkembangnya dunia industri dewasa ini menuntut adanya perkembangan khususnya dalam hal peningkatan efisiensi produksi. Kecepatan, ketepatan, kepresisian, serta kuantitas produksi menjadi suatu suatu hal yang harus dipenuhi pada setiap proses produksi. Robot lengan dapat didesain dengan berbagai jenis sesuai dengan fungsi dan kebutuhan user. Misalnya saja pengendalian lengan robot dapat dilakukan secara nirkabel dengan menggunakan modul protocol Zigbee dan LabView sebagai antarmukanya sehingga memudahkan user untuk mengendalikan lengan robot tersebut secara remote (Nandhini, Shabatini, \& Karthikeyan, 2015). 
Konsep lengan robot juga dapat dikombinasikan dengan robot beroda yang fungsinya menjadi lebih variatif. Salah satu aplikasinya adalah dengan ditambahkan sensor cahaya (untuk image processing) dan sensor sentuh untuk pengikut garis serta mengetahui lokasi awal. Kombinasi ini dapat didesain sebagai mobile platform untuk memindahkan objek tertentu dan memindahkannya ke suatu tempat (Guo, Hsia, Su, \& Wang, 2016). Contoh kombinasi lain adalah dengan ditambah beberapa fitur seperti sensor CO, detak jantung, dan suhu tubuh, aplikasi robot ini dapat digunakan lebih luas misalnya saja sebagai asisten pribadi untuk manula (Yang, Song, Li, Shan, \& Guo, 2015).

Fokus penletian ini adalah pada penggunaan lengan robot sebagai actuator utama dan sensor warna sebagai masukannya. Sabagai acuan, lengan robot serupa dengan 3-DOF telah dibuat dengan menggunakan inverse kinematics sebagai metode pergerakannya (Sumardi, Febriramadhan, \& Triwiyatno, 2016). Selain lengan robot, konsep sensor warna sebagai sortir objek berdasarkan warna juga diterapkan dengan menggunakan delta robot yang digunakan untuk mensortir kualitas buah-buahan (Reyes, Badillo, López, \& Mora, 2016). Dari paparan tentang aplikasi robot lengan tersebut, maka pada penelitian ini mengadopsi system lengan robot untuk mengklasifikasikan beberapa objek sesuai dengan warna objek tersebut.

\section{METODE}

Secara garis besar, penelitian ini digambarkan dalam tahapan/ alur rancang bangun pada Gambar 1.

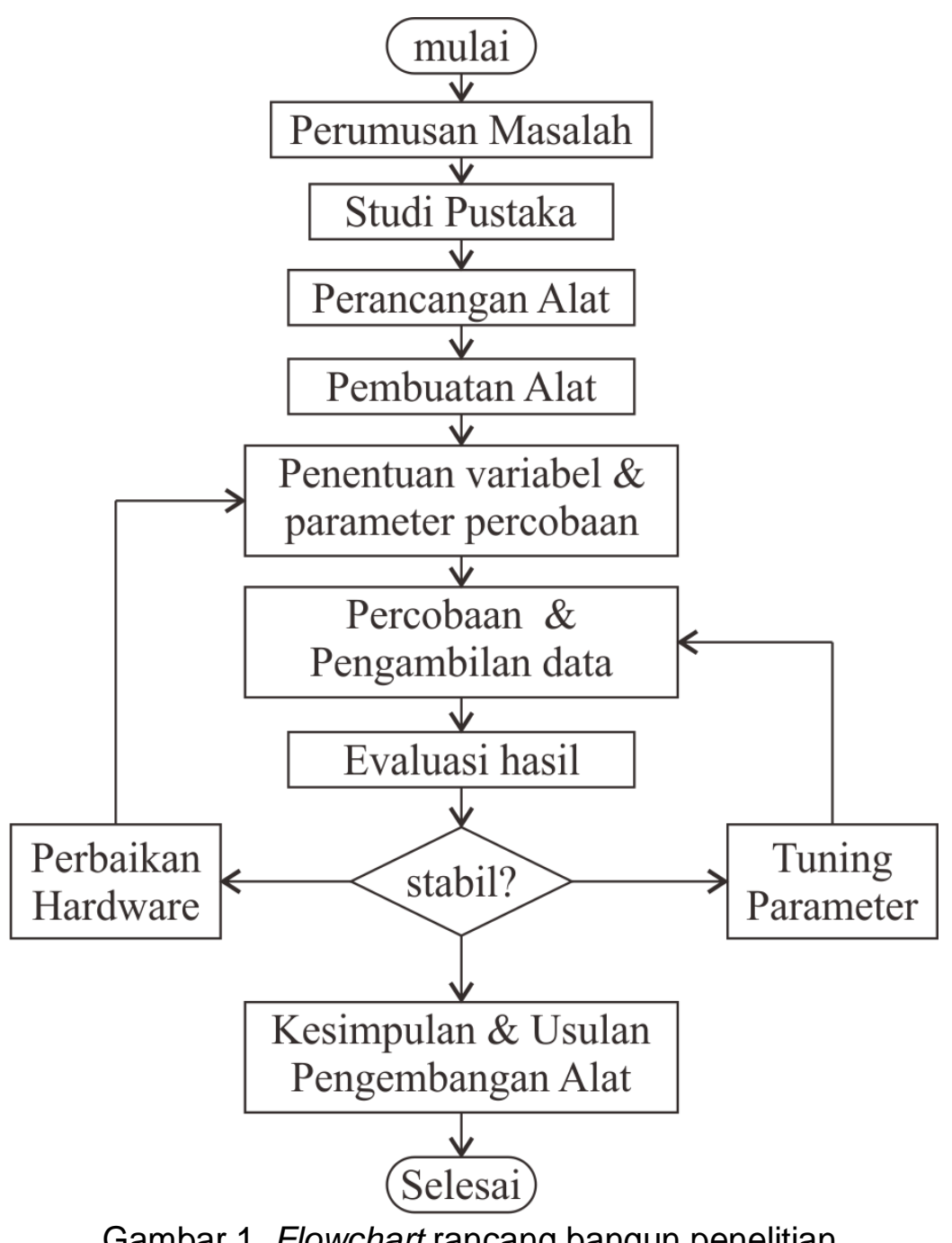

Gambar 1. Flowchart rancang bangun penelitian 
Metode yang digunakan dalam penelitian ini adalah sebagai berikut.

1. Studi literatur dengan mempelajari beberapa referensi seperti buku-buku dan artikel penunjang, sebagai bahan acuan untuk mengkaji teori-teori dasar dan menambah wawasan tentang pembuatan mekanik lengan robot dan sensor warna

2. Mempelajari model lengan robot pengklasifikasi objek berdasarkan warna yang telah dibuat sebelumnya sebagai landasan untuk mengembangkannya ke dalam bentuk yang lebih sempurna.

3. Pembuatan perangkat-keras dan perangkat-lunak menggunakan teori dan referensi yang telah ada untuk mendapatkan hasil sesuai dengan yang diinginkan.

4. Melakukan pengamatan untuk mengetahui dan memahami cara dan unjuk kerja perangkat-keras dan perangkat-lunak yang telah dibuat.

5. Pembuatan analisis dan kesimpulan hasil pengamatan.

\section{HASIL DAN PEMBAHASAN}

Hasil perancangan dari penelitian ini dibagi menjadi dua bagian utama, yakni perancangan perangkat keras (mekanik dan rangkaian elektronik) dan perangkat lunak.

Perancangan perangkat keras sistem ini terdiri dari beberapa bagian, yakni mekanik, sistem minimum mikrokontroler AVR ATMEGA32, sensor warna, penampil LCD 2x16, tombol menu, dan baterai sebagai power supply untuk keseluruhan sistem. Secara umum robot ini memiliki diagram blok yang ditunjukkan pada Gambar 2.

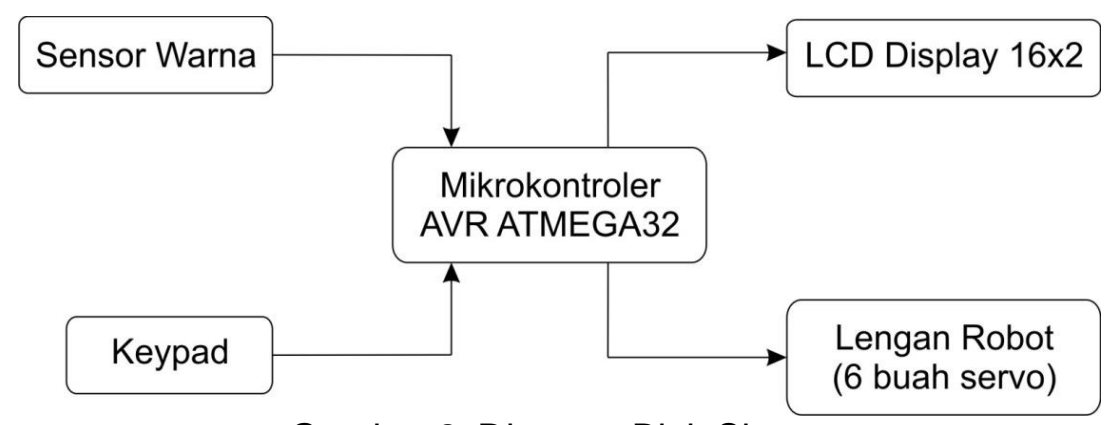

Gambar 2. Diagram Blok Sistem

Robot lengan ini memiliki 4 (empat) derajat kebebasan (DOF) dan tersusun atas 6 buah servo yang memiliki torsi berbeda-beda, yakni empat buah servo dengan torsi $10 \mathrm{~kg}$ (HS-5645MG) dan dua buah servo dengan torsi $3 \mathrm{~kg}$ (HS-311). empat buah servo tersebut memiliki torsi yang lebih besar karena beban yang ditanggung juga lebih besar. Satu buah sebagai tumpuan keseluruhan lengan, dua buah untuk mengangkat ruas lengan utama (digabung menjadi satu) dan satu buah untuk mengangkat lengan penjepit. Sedangkan servo dengan torsi lebih kecil hanya digunakan pada bagian penjepit objek saja. Rancangan bentuk robot lengan dalam Free Body Diagram (FBD) dan konfigurasi robot secara keseluruhan tersaji pada Gambar 3(a) dan Gambar 3(b).
Objek yang digunakan berbentuk kubus dan dibuat dari bahan styrofoam dengan ukuran $5 \times 4 \times 5.5 \mathrm{~cm}$ dan dibagi menjadi 4 jenis warna yakni merah, hijau, biru, dan hitam. Sebagai tempat objek sebelum disortir, digunakan konveyor statis yang memanfaatkan bidang miring. Penempatan objek juga diacak. Setelah discan warnanaya, objek akan di pindahkan ke dalam wadah yang telah disediakan berdasarkan warna yang terbaca. Desain objek dan konveyor statis ini ditunjukkan pada Gambar 4(a) dan Gambar. 4(b). Sedangkan untuk denah pemasangan komponen-komponen mekanik berupa robot lengan, objek, konveyor dan wadah diatas disusun sesuai dengan bagan pada Gambar. 5 . 


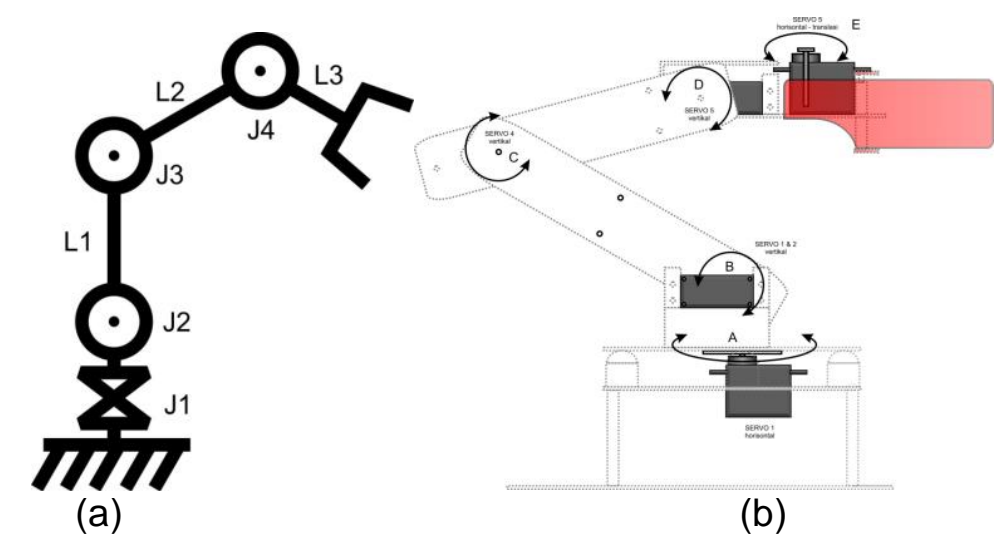

Gambar 3(a) Rancangan bentuk robot lengan dalam Free Body Diagram (FBD).

(b) Konfigurasi Robot Lengan

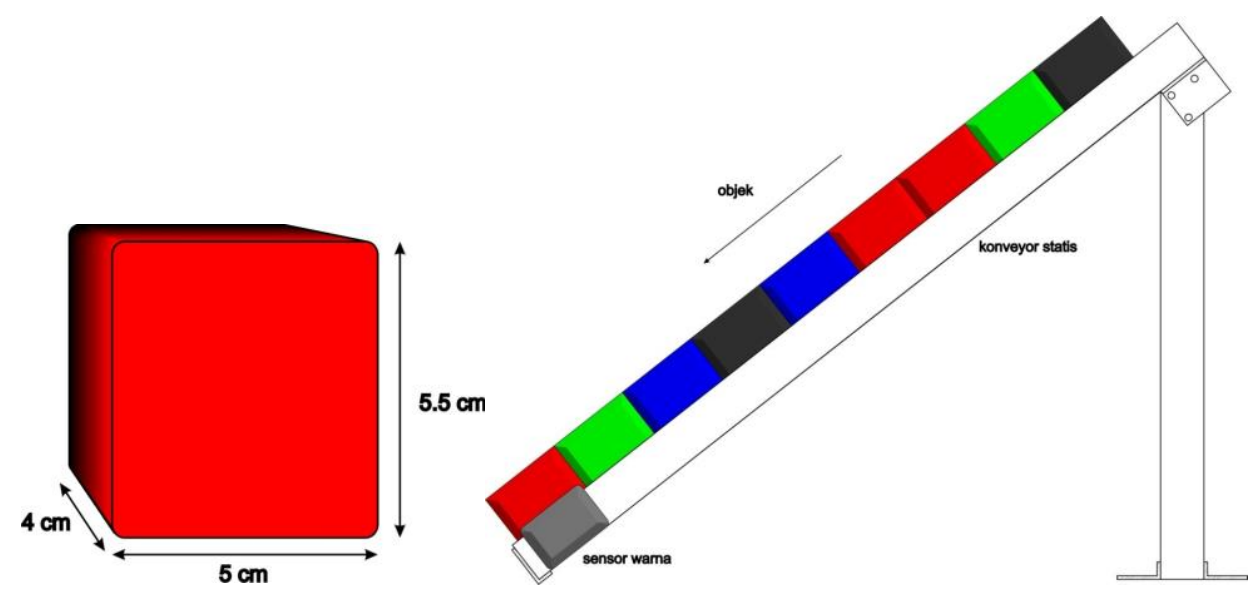

Gambar 4(a) objek yang akan disortir. (b) konveyor stastis berbentuk bidang miring.

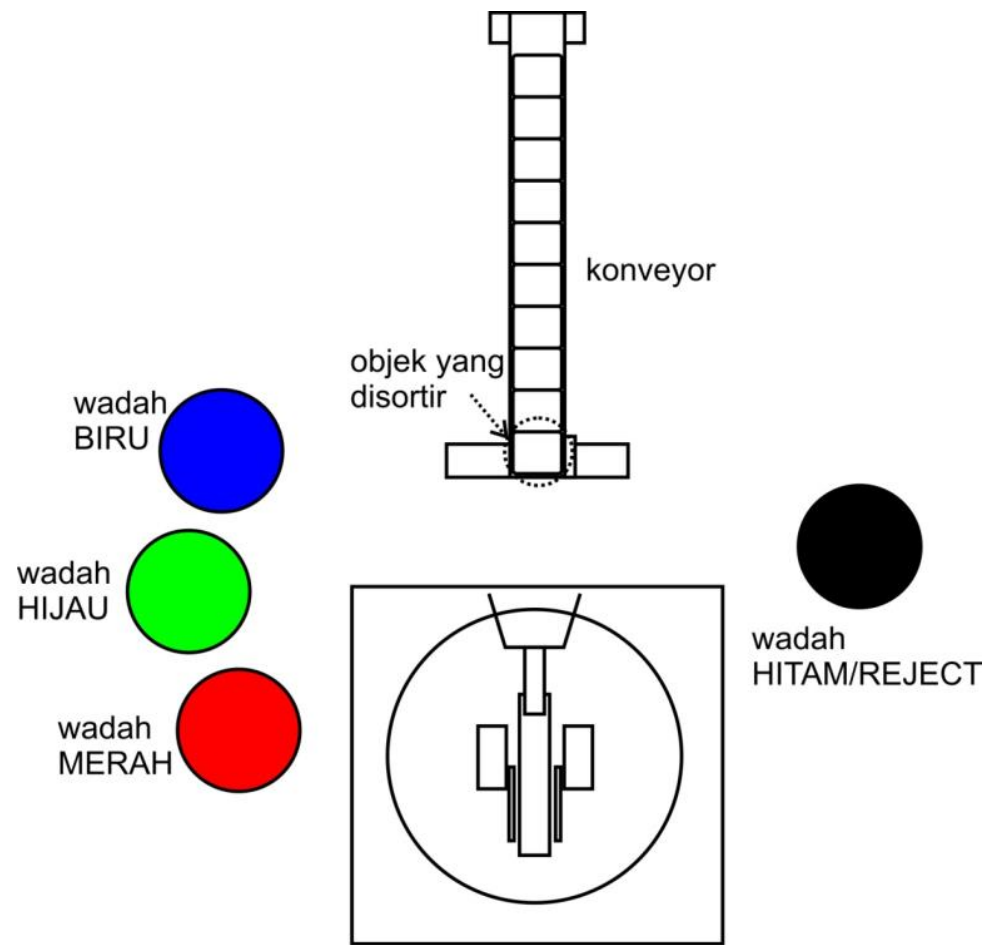

Gambar 5. Workspace robot lengan dan objek

Jurnal Sains dan Teknologi | 293 
Robot ini hanya menggunakan satu buah chip pengontrol yaitu mikrokontroler ATMega32. Mikrokontroler ini memiliki 32 pin $\mathrm{I} / \mathrm{O}$ dan digunakkan sebagai jalur masukan dan keluaran semua sistem elektronika pada robot ini. Mikrokontroler ini memiliki kapasitas memori flash yang cukup untuk menampung semua program untuk sistem ini yaitu 32kbyte. Keunggulan dari mikrokontroler ini yaitu memiliki fasilitas ADC (Analog to Digital Converter) sebagai masukan sinyal sensor warna. Semua sistem elektronika dapat dilihat pada rangkaian pada Gambar 6 .

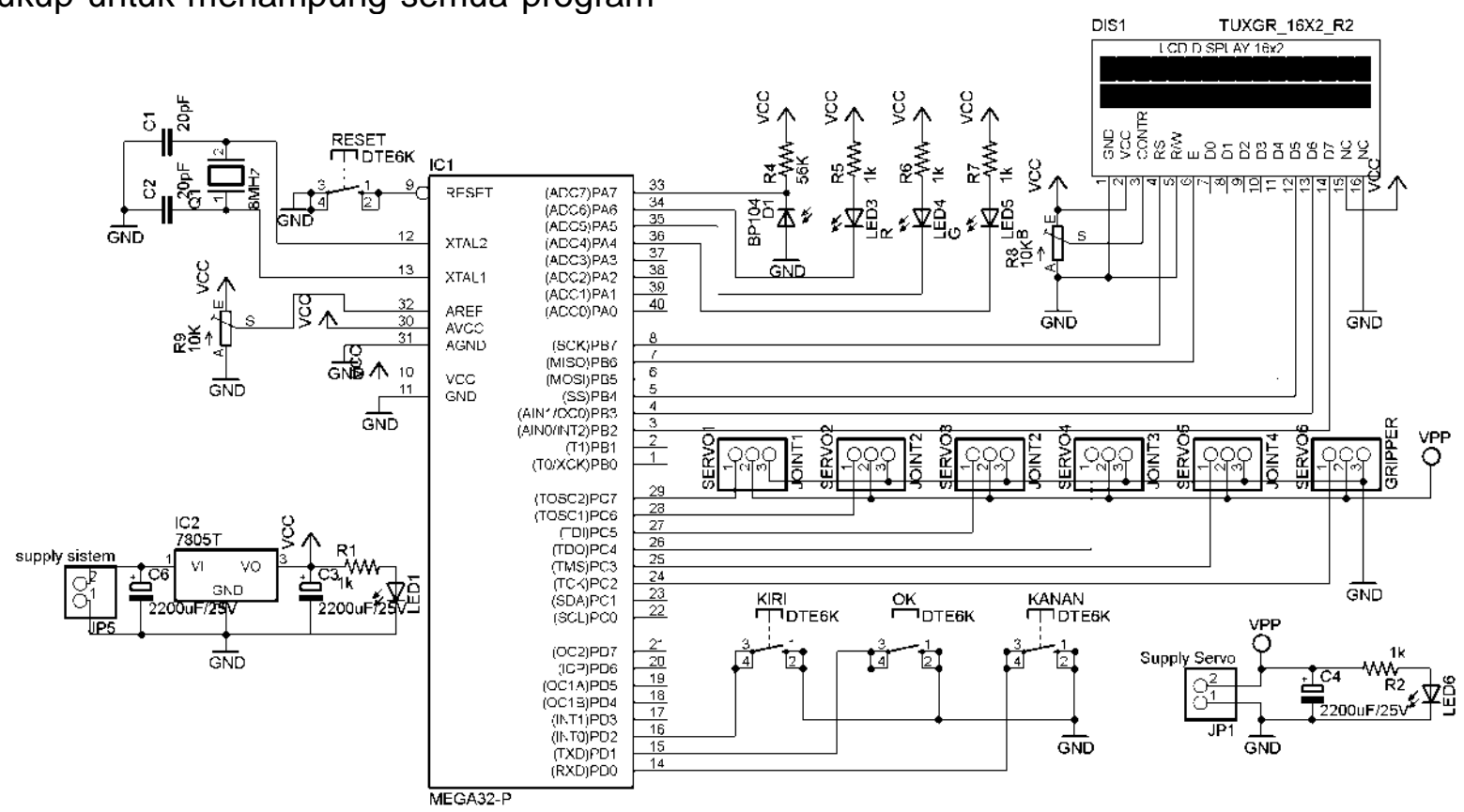

Gambar 6. Rangkaian elektronik untuk keseluruhan Sistem

Sebagai masukan, sensor warna terdiri dari 1 buah photodiode dan 3 buah LED superbright yang terdiri dari warna primer RGB (Red, Green, Blue) yaitu merah, hijau, dan biru. Ketiga LED warna tersebut akan menyala bergantian dan diatur oleh pin mikrokontroler dengan proses sistem bergantian(scanning).

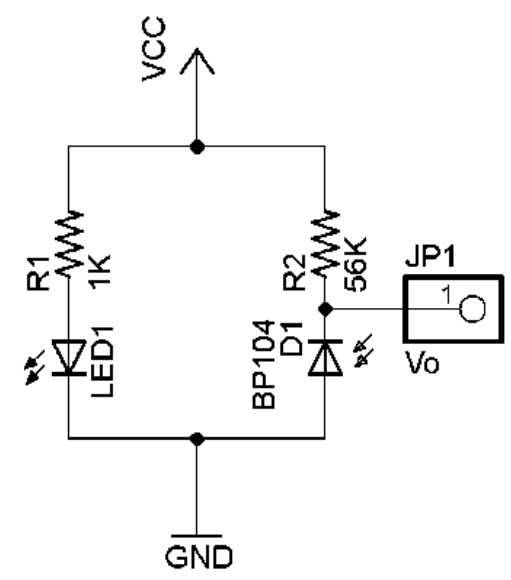

Gambar 7. Rangkaian pembagi tegangan pada sensor warna
Keluaran dari rangkaian pembagi tegangan sensor akan dibaca oleh pin ADC internal mikrokontroler. Setiap warna LED yang dipancarkan akan memantulkan intensitas cahaya yang berbeda-beda pada setiap warna objek. Rangkaian sensor ini merupakan rangkaian pembagi tegangan yang dapat dilihat pada Gambar 7 . Sehingga untuk mencari output tegangan Vo, berlaku persamaan (1):

$V_{o}=\frac{R_{D 1}}{R_{D 1}+R_{2}} x V C C$

Berikutnya, bagian perangkat lunak terdiri dari bagian utama, pembacaan sensor warna, kalibrasi, dan penyimpanan variable warna. Program utama dari sistem otomasi ini adalah berupa proses pengenalan objek an peletakan objek tersebut berdasarkan warnanya.proses ini ditunjukkan oleh diagram alir pada Gambar 8.

Jurnal Sains dan Teknologi | 294 

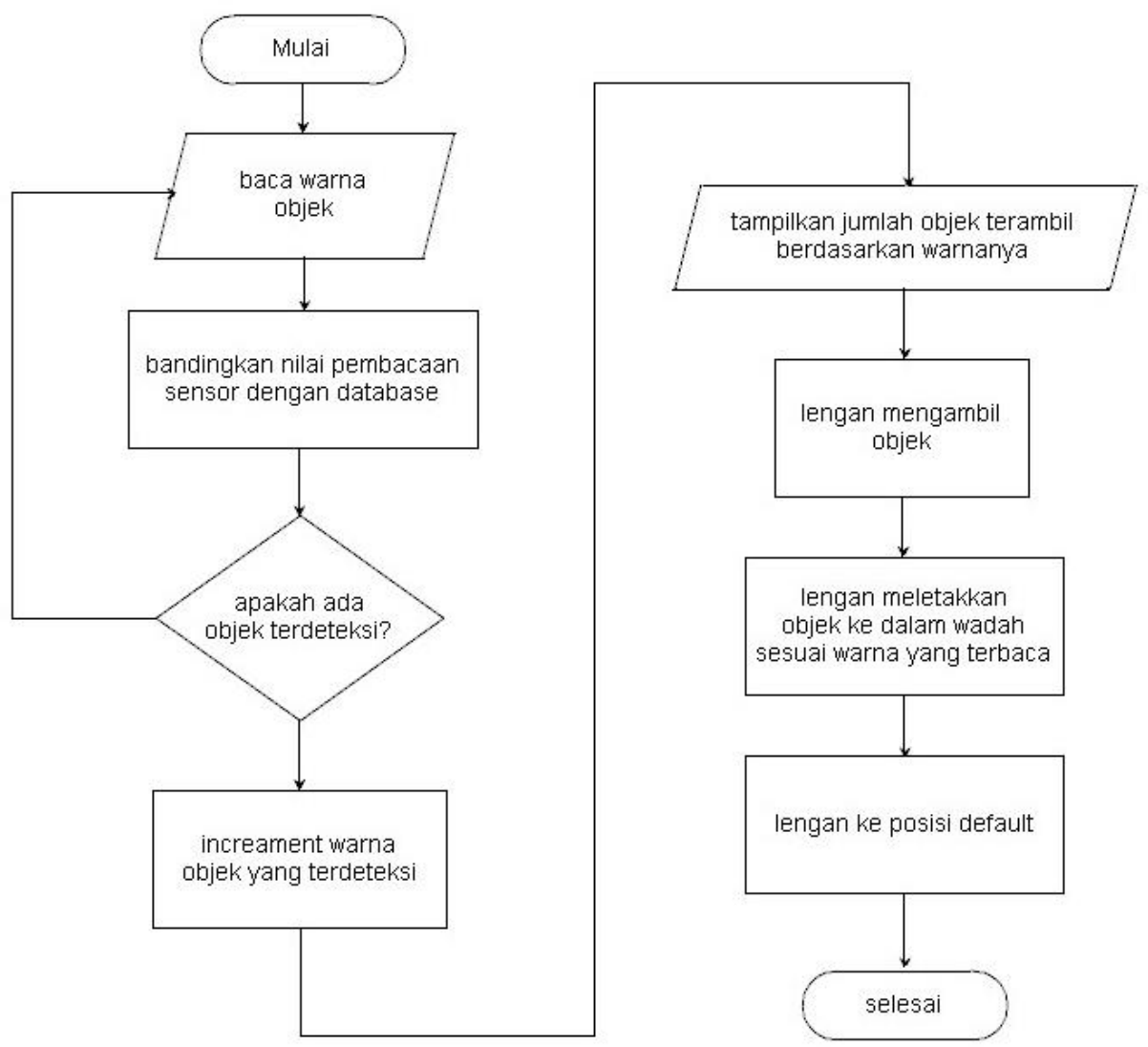

Gambar 8. Diagram alir program utama

Tahapan proses sortir objek ini adalah sebagai berikut. Pertama-tama, lengan berada pada posisi default kemudian dilakukan pembacaan nilai sensor warna dengan pemanggilan sub program cek warna objek dengan melakukan perbandingan nilai pembacaan sensor warna dengan database warna yang telah disimpan sebelumnya. Kemudian LCD menampilkan jumlah objek yang telah disortir berdasarkan warnanya di baris kedua. apabila tidak ada objek terdeteksi, program akan kembali ke posisi default. Selanjutnya, LCD menampilkan warna objek seiring dengan pengambilan objek oleh lengan pada konveyor. Tahap terakhir lengan meletakkan objek pada wadah sesuai warnanya

Perubahan intensitas cahaya yang mengenai photodiode akan ditandai dengan perubahan nilai tegangan pada keluaran sensor hasil pembagi tegangan. Nilai tegangan ini akan dibaca oleh ADC 10-bit internal mikrokontroler dan dikonversikan menjadi nilai bilangan desimal pada sebuah variable antara 0 hingga 1023, nilai konversi dapat dihitung dari persamaan (2).

$A D C=\frac{V_{\text {in }}}{V_{\text {reff }}} \times 1023$

Mikrokontroler pada robot ini konfigurasi nilai referensi ADC diambil dari pin AVCC yaitu 5 volt sehingga nilai VReff adalah 5 volt. Untuk membaca dan mengambil data ADC digunakan perintah Getadc(channel).

Proses pembacaan warna objek ini menggunakan fasilitas ADC channel(0). Masing-masing nilai yang mewakili intensitas warna yang terbaca oleh photodioda tersebut memiliki variabel yang terpisah, yakni variabel data_r untuk merah, data_g untuk hijau, dan data_b untuk biru. Untuk mengambil besarnya nilai tesebut, maka LED yang bersangkutan harus dihidupkan terlebih dahulu, yakni dengan memberi logika 0 (low) pada LED bersangkutan secara bergantian selama beberapa saat 
(led_r, led_g, atau led_b). Dalam program ini, proses penyalaan masing-masing LED dan pembacaan nilai ADC membutuhkan waktu sekitar $200 \times 500 \mu \mathrm{S}=100.000 \mu \mathrm{S}=100 \mathrm{mS}$.

Proses kalibrasi dan penyimpanan warna-warna objek yang akan digunakan dapat diakses pada sub menu set_rgb. Dalam sub menu ini, program membaca warna objek dengan mengambil data RGB pada sub program baca_rgb. Tiap-tiap objek memiliki nilai-nilai yang berbeda untuk masing-masing warnanya. Setiap satu warna, memiliki tiga buah nilai ADC, yakni yang tersimpan pada variabel data_r, data_g dan data_b. Digunakan 5 macam data warna yang disimpan, yakni none (tanpa objek), merah, hijau, biru, dan hitam. Hasil pembacaan sensor terlebih dahulu disimpan ke dalam RAM, kemudian baru disimpan ke dalam EEPROM. Penyimpanan ke dalam EEPROM ini bertujuan agar data referensi warna yang tersimpan tidak hilang ketika supply dimatikan sehingga lebih efisien karena ketika alat dinyalakan kembali, tidak perlu dilakukan setting warna tiap-tiap objek lagi.
Metode yang dilakukan dalam proses pengenalan warna objek ini adalah dengan metode pendekatan. Semakin sedikit selisih nilai yang terbaca sensor dengan dengan nilai referensi yang tersimpan, berarti warna objek tersebut sesuai dengan referensi warna bersangkutan. Langkah pertama yang dilakukan adalah dengan membaca nilai sensor saat ini. Kemudian, dicari selisihnya dengan nilai antara variabel yang tersimpan. Selisih-selisih (masing-masing variabel) tersebut dijumlahkan. Kemudian, nilai selisih yang paling sedikit merupakan nilai warna bersangkutan. Dalam sub program ini, selain melakukan pengecekan warna, juga melakukan perhitungan (penjumlahan) warna objek yang terdeteksi, sehingga sistem mengetahui berapa jumlah warna yang telah disortir. Sebagai contoh, jika nilai selisih warna biru lebih kecil daripada warna merah, hijau, hitam, dan tanpa objek, berarti objek tersebut berwarna biru. Flowchart untuk setiap pembacaan warna objek ditampilkan pada Gambar 9 .

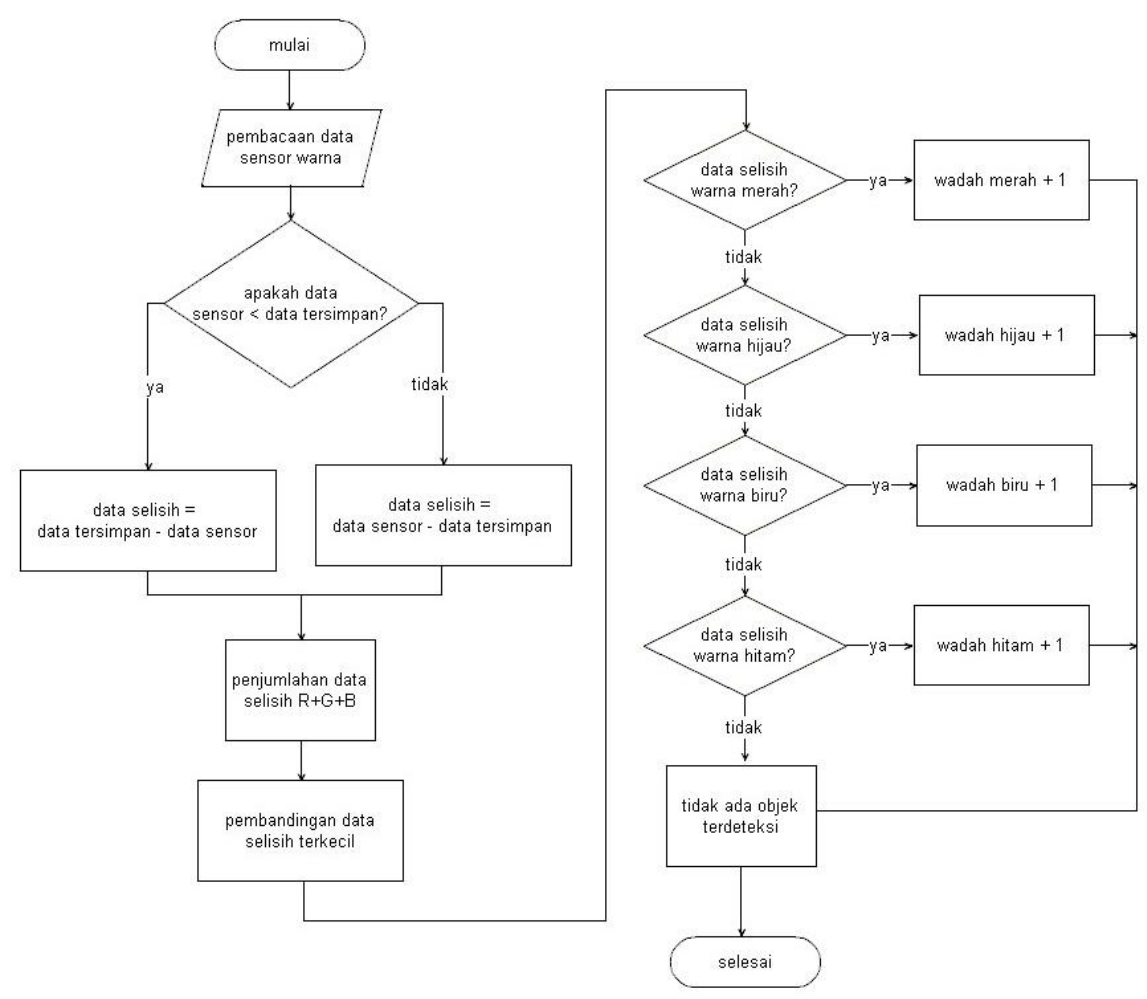

Gambar 9. Diagram alir proses pembacaan objek

Komponen sensor yang digunakan untuk mendeteksi warna objek adalah photodiode dan dipasang secara berpasangan dengan tiga LED superbright 
warna merah, hijau, dan biru yang menyala bergantian. Dalam robot ini digunakan sensor photodiode karena karakteristiknya yang paling memenuhi untuk sensor warna dan digunakan LED superbright sebagai sumber cahaya karena LED ini cukup terang untuk memberi pantulan pada objek berwarna putih dan cahayanya cukup teredam oleh lantai berwarna hitam(garis). Sensor ini dipasang pada konveyor dan akan bekerja hanya pada saat proses pembacaan warna objek saja. Pembacaan nilai ADC dari keluaran sensor akan bergantian sesuai dengan warna yang sedang dipancarkan.

Rangkaian pembagi tegangan sensor pada Gambar 7 memberikan nilai keluaran berupa tegangan antara 0 hingga 5 volt yang berubah mengikuti intensitas pantulan cahaya yang mengenainya dan akan dibaca oleh pin ADC lalu dikonversikan menjadi bilangan desimal pada setiap variable warnanya dengan nilai antar 0 hingga 1023 (2). Nilai tegangan keluaran sensor saat proses scanning tidak dapat dibaca oleh multimeter karena perubahan tegangan untuk masing-masing warna sulit dibedakan karena terlalu cepat proses scanning atau pergantian nyala LED-nya. Untuk pengujian nilai RGB (Red, Green, Blue) hasil pantulan objek yang diuji akan dilihat langsung pada variable hasil konversi ADC. Hasil pembacaan tersebut dilihat pada LCD untuk menampilkan nilai ADC untuk setiap intensitas warna yang dipantulkan dan dicatat pada Tabel 1 dan dipresentasikan oleh grafik pada Gambar 10.

Tabel 1. Data pengukuran nilai ADC sensor warna

\begin{tabular}{ccccc}
\hline No. & Warna & $\begin{array}{c}\text { ADC } \\
\text { Merah }\end{array}$ & $\begin{array}{c}\text { ADC } \\
\text { Hijau }\end{array}$ & $\begin{array}{c}\text { ADC } \\
\text { Biru }\end{array}$ \\
\hline 1 & Merah 1 & 38 & 788 & 671 \\
2 & Merah 2 & 38 & 735 & 646 \\
3 & Merah 3 & 36 & 804 & 655 \\
4 & Hijau 1 & 752 & 288 & 452 \\
5 & Hijau 2 & 758 & 295 & 550 \\
6 & Hijau 3 & 780 & 231 & 465 \\
7 & Biru 1 & 738 & 582 & 30 \\
8 & Biru 2 & 725 & 477 & 27 \\
9 & Biru 3 & 730 & 496 & 30 \\
10 & Hitam 1 & 794 & 830 & 686 \\
11 & Hitam 2 & 793 & 760 & 650 \\
12 & Hitam 3 & 829 & 743 & 636 \\
13 & Tidak & 850 & 160 & 618 \\
\hline & ada & & & \\
\hline
\end{tabular}

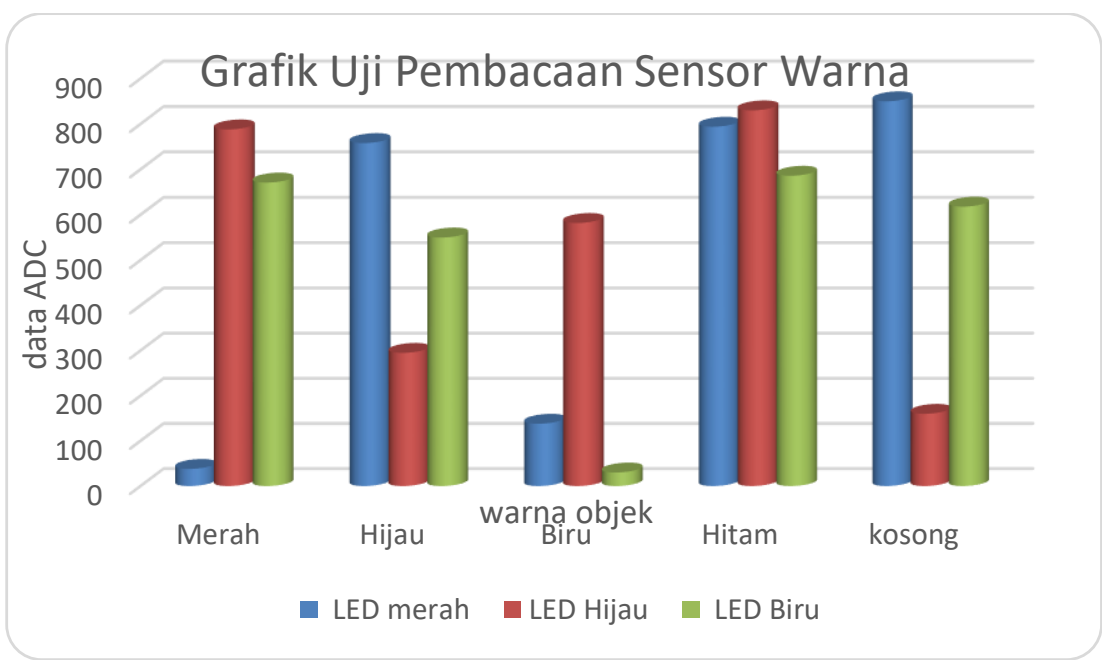

Gambar 10. Grafik uji pembacaan sensor warna 
Secara umum, keseluruhan sistem robot ini dapat berjalan dengan sebagaimana mestinya. Kecepatan perputaran servo berpindah dari posisi sekarang menuju posisi tujuan sangat bergantung pada pemberian nilai waktu tunda. Pada Tabel 2 disajikan waktu yang dibutuhkan untuk mengambil dan meletakkan tiap-tiap objek berdasarkan waktu tunda yang diberikan pseperti pada potongan sub program diatas. Pengukuran ini dilakukan dengan menggunakan stopwatch.

Tabel 2. Waktu yang dibutuhkan lengan untuk sortir objek (dalam detik)

\begin{tabular}{ccccc}
\hline Warna & Pengambilan & peletakan & $\begin{array}{c}\text { Kembali ke posisi } \\
\text { awal }\end{array}$ & Total \\
\hline Merah & 2,6 & 4,8 & 2,6 & 10,0 \\
Hijau & 2,6 & 4 & 2,3 & 8,9 \\
Biru & 2,6 & 3,5 & 1,9 & 8,0 \\
Hitam & 2,6 & 4,8 & 2,5 & 9,9 \\
\hline
\end{tabular}

Dari Tabel 2 terlihat bahwa waktu yang dibutuhkan lengan robot untuk mengambil semua tipe warna objek adalah sama, yakni 2,6 detik. Sedangkan waktu total yang diperlukan lengan robot dari mengambil objek, peletakan objek sesuai warnanya dan lembali ke posisi awal adalah pada rentang 8,0 hingga 10,0 . Sehingga rata-rata waktu yang diperlukan lengan robot ini dalam menyelesaikan tugasnya dapat dihitung dengan persamaan 3 .

$$
\begin{aligned}
\bar{x} & =\frac{\sum_{i=1}^{n} x_{i}}{n} \\
& =\frac{10^{2}+8,9+8,0+9,9}{4} \\
& =9,2 \text { detik }
\end{aligned}
$$

Rata-rata waktu yang terhitung pada persamaan 3 diatas bergantung pada desain robot, layout peletakan objek, dan spesifikasi motor servo yang digunakan sebagai actuator.

\section{SIMPULAN}

Berdasarkan hasil ujicoba dan analisa data dari penelitian, maka dapat diambil kesimpulan bahwa dengan menggunakan motor servo bertorsi besar, gerak lengan menjadi stabil (tidak terganggu berat dari link dan motor servo pada lengan itu sendiri). Robot lengan ini dapat menyelesaikan tugas mengangkut dan meletakkan objek berwarna merah dengan waktu 10 detik, objek hijau 8,9 detik, objek biru 8 detik, dan hitam 9,9 detik. Tuning posisi dan sudut tiap joint dapat dilakukan dengan berbagai metode, namun untuk mendapatkan hasil yang sesuai, diperlukan percobaan trial and error dengan mempelajari karakteristik sistem serta memperhatikan faktor eksternal yang mempengaruhinya.

Untuk penelitian selanjutnya sebaiknya ditambahkan beberapa hal yang dapat meningkatkan dan mengembangkan kinerja sistem, salah satunya adalah kontrol sistem dapat dipadukan dengan beberapa kontrol lain seperti kendali PID dan logika samar (fuzzy logic) sebagai algoritma penentuan konstanta yang lebih baik dan akurat. Selain itu, penggunaan perlu diterapkan agar output dari kontrol lengan lebih presisi dan akurat. Selebihnuya, algoritma untuk pemetaan (mapping) workspace robot dapat digunakan algoritma yang lebih cerdas seperti algoritma adaptif dan NLP, namun perlu ditambahkan sensor lain.

\section{DAFTAR PUSTAKA}

Guo, J., Hsia, K.-H., Su, K.-L., \& Wang, J.-T. (2016). Development of the Mobile Robot with a Robot Arm. (pp. 16481653). IEEE. 
Nandhini, J., Shabatini, K., \& Karthikeyan, S. (2015). Wireless Colour Sensing Arm Robot. International Conference on Robotics, Automation, Control and Embedded Systems. Chennai, India: IEEE.

Reyes, J. D., Badillo, G. G., López, V. E., \& Mora, G. G. (2016). OBJECT'S COLOR CLASIFICATION AND REPOSITIONING OPERATED BY A DELTA ROBOT. Congreso Mexicano de Robótica (XVIII COMRob 2016). Sinaloa, México: IEEE.

Sumardi, Febriramadhan, L., \& Triwiyatno, A. (2016). Design of Color Based
Object Sorting Through. Int. Conf. on Information Tech., Computer, and Electrical Engineering (ICITACEE) (p. Arm Manipulator with Inverse Kinematics Method). Semarang, Indonesia: IEEE.

Yang, L., Song, X., Li, Y., Shan, H., \& Guo, J. (2015). Design and Experimental Research on Intelligent household Assistive Robot for the Elderly. Fifth International Conference on Instrumentation and Measurement, Computer, Communication and Control. IEEE. 